\title{
Utilidad de la proteína C-reactiva en la sepsis neonatal temprana
}

\section{Utility of C-reactive protein in early neonatal sepsis}

\author{
Antonio C. Puello Ávila ${ }^{1}$ y Andrea E. Cataño Villegas ${ }^{2}$
}

${ }^{1}$ Fellow de Neonatología Universidad El Bosque.

${ }^{2}$ Médico Autónoma de las Américas.

No hubo financiamiento externo

Los autores declaran ausencia de conflictos de interés

Recibido: 19 de noviembre de 2020 / Aceptado: 5 de marzo de 2021

\section{Resumen}

Introducción: La baja sensibilidad y especificidad de las ayudas diagnósticas y el bajo aislamiento en los cultivos dificulta el reconocimiento de la sepsis bacteriana de inicio temprano en neonatos. Objetivo: Determinar la validez diagnóstica de la de la proteína $\mathrm{C}$ reactiva (PCR) en la sepsis en la sepsis neonatal temprana. Método: Se evaluó el papel de la PCR en el diagnóstico de sepsis neonatal temprana. Las concentraciones se midieron a las 12 y $48 \mathrm{~h}$ de vida en pacientes con sospecha de sepsis. Al evaluar la sensibilidad y especificidad de la PCR, se utilizó el resultado de manera cuantitativa y mediante una curva ROC no paramétrica se estimó sensibilidad y especificidad, razones de verosimilitud y porcentaje de clasificación correcta para cada punto de corte posible. Resultados: El estudio incluyó 198 pacientes. La sensibilidad, especificidad, valor predictor positivo (VPP), valor predictor negativo (VPN), índice de probabilidad positiva e índice de probabilidad negativa de la PCR fue de 72,2 - 82,4 - 45,2 - 93,7 - 4,1 y 0,3 , respectivamente con área bajo la curva de 0,78 . Conclusiones: La PCR es particularmente útil para descartar una infección. Dos PCR seriadas negativas en ausencia de expresión clínica y de hemocultivos positivos tienen un alto VPN y un índice de probabilidad negativa a favor de excluir la infección con una alta certeza y/o de descontinuar la terapia antibiótica.

Palabras clave: sepsis neonatal de inicio temprano, proteína Creactiva.

\section{Abstract}

Background: The low sensitivity and specificity of diagnostic aids and the low isolation in cultures make it difficult to recognize early-onset bacterial sepsis in neonates. Aim: Determine the diagnostic validity of $\mathrm{C}$ reactive protein (CRP) in early neonatal sepsis. Method: The role of CRP in the diagnosis of early-onset neonatal sepsis was evaluated. Levels were measured at 12 and 48 hours of life in patients with suspected sepsis. When evaluating the sensitivity and specificity of the CRP, the result was used quantitatively, using a non-parametric ROC curve to estimate sensitivity and specificity, likelihood ratios and percentage of correct classification for each possible cut-off point. Results: The study included 198 patients. The sensitivity, specificity, positive predictive value, negative predictive value, positive probability index and negative probability index of CRP, were 72.2 - $82.4-45.2$ - $93.7-4.1$, and 0.3 , respectively with area under the curve of 0.78 . Conclusions: CRP is particularly useful to rule out infection. Two negative serial CRP in the absence of clinical symptoms and positive blood cultures have a high negative predictive value and a negative probability index in favor of excluding infection with high certainty and/or discontinuing antibiotic therapy.

Keywords: early-onset neonatal sepsis, C-reactive protein. 


\section{Introducción}

L a sepsis neonatal de origen bacteriano es una patología con una potencial letalidad, por lo que requiere de diagnóstico urgente. Del total de muertes neonatales, la sepsis representa al $73 \%$ de los casos durante este periodo ${ }^{1}$. La baja sensibilidad y especificidad de las ayudas diagnósticas y el bajo aislamiento en los cultivos dificulta el reconocimiento ${ }^{2}$. La habilidad de las pruebas de laboratorio y las reglas de predicción para identificación fluctúan entre pobre y moderada ${ }^{3}$, y su utilización sin tener en cuenta sus limitaciones, lleva a sobre diagnosticar y sobre tratar, o a dejar de detectar oportunamente la sepsis neonatal aumentando la mortalidad, o lleva a iniciar manejos tardíos con efectividad reducida ${ }^{4}$. Como resultado, los médicos suelen tratar a los bebés sanos durante períodos prolongados de tiempo, incluso cuando los cultivos bacterianos son negativos; es así como el uso prolongado (> 5 días) de antibioterapia empírica en ausencia de aislamiento microbiológico está relacionado con riesgo aumentado de enterocolitis y muerte ${ }^{5}$

La proteína $\mathrm{C}$ reactiva (PCR) es la prueba más utilizada para el diagnóstico de sepsis neonatal tempra$\mathrm{na}^{4}$. La validez de una única prueba para la detección inicial es baja (sensibilidad $=17,16 \%$, especificidad $=58,33 \%$, valor predictor positivo $(\mathrm{VPP})=72,72 \%$ y valor predictivo negativo $(\mathrm{VPN})=9,81 \%)^{6}$; existen múltiples situaciones maternas y fetales, además de las infecciones, asociadas a elevación de las concentraciones, y que afectan su sensibilidad y especificidad ${ }^{7}$. Su determinación mejora el rendimiento diagnóstico al realizar mediciones seriadas a las 24 y $48 \mathrm{~h}$ después de la aparición de los síntomas tempranos de sepsis ${ }^{8}$ y genera una buena recomendación para descontinuar la terapia antimicrobiana cuando se encuentran dos valores seriados negativos (VPN de 99,7\% y un coeficiente de probabilidad negativa de 0,15$)^{9}$.

La procalcitonina es otro marcador usado en sepsis neonatal temprana, más sensible comparada con la PCR, pero menos específica ${ }^{10}$; los neonatos tienen un pico fisiológico en las primeras $48 \mathrm{~h}$, motivo por el cual la especificidad no supera el $65 \%$ y tiene un pobre VPP ${ }^{11}$.

El hemograma es una prueba de uso frecuente y de fácil acceso en los lugares con recursos limitados, lo que ha llevado a su uso común, como prueba para el diagnóstico; sin embargo, no se ha demostrado alguna utilidad diagnóstica, careciendo de sensibilidad y VPP ${ }^{12}$.

El estándar de oro para el diagnóstico continúa siendo los hemocultivos. Su dificultad radica en los pocos aislamientos, que pueden variar entre 30 y $40 \%{ }^{13}$. La razón de esta consideración podría estar en relación a muestras insuficientes al momento de la toma ${ }^{14,15}$ o por el uso de antimicrobianos en la madre antes del parto ${ }^{16}$.
A pesar de los nuevos marcadores, la PCR es el reactante más ampliamente estudiado hasta ahora ${ }^{17}, \mathrm{y}$ sigue siendo el índice preferido en muchas unidades de cuidados intensivos neonatales ${ }^{18}$. El objetivo fue determinar la validez diagnóstica de la PCR en la sepsis neonatal temprana.

\section{Materiales y Métodos}

\section{Tipo de estudio y diseño}

Durante un período de 10 meses, de junio-2016 a marzo-2017, se realizó un estudio de cohorte concurrente, en una población de recién nacidos atendidos en una unidad de cuidados intensivos neonatales de un hospital público de alta complejidad obstétrica, y sitio principal de referencia de la ciudad de Cartagena (Colombia). Todos los neonatos que nacieron con clínica de infección $\mathrm{y} / \mathrm{o}$ tuvieran al menos un factor de riesgo infeccioso $\mathrm{y} / \mathrm{o}$ la combinación de factores de riesgo (corioamnionitis, rotura prolongada de membranas mayor a $18 \mathrm{~h}$, tamizaje positivo para Streptococcus agalactiae, hijo previo con infección bacteriana grave por $S$. agalactiae, prematurez sin causa, ausencia de control prenatal, infección de vías urinarias activa en la madre en el momento del parto, vaginosis bacteriana o fiebre materna) que hubieran sido hospitalizados durante ese período bajo sospecha de sepsis neonatal de inicio temprano, fueron incluidos en el estudio. Por la tasa alta de madres en esta población con ausencia de control prenatal, sin ningún estudio en el momento del parto, por consenso institucional se incluyó también esta variable como un factor de riesgo para sepsis temprana. El bajo peso no se consideró como un factor de riesgo independiente, sino que fue un factor que se asoció en combinación con otros factores de riesgo. Se excluyeron aquellos recién nacidos que hubiesen sido remitidos de otras instituciones, que padecieran alguna otra enfermedad grave no infecciosa o quirúrgica, malformación mayor, con muy bajo peso al nacer o extremadamente prematuro.

\section{Recolección y procesamiento de las muestras}

A todos los pacientes que al nacer cumplían los criterios de inclusión se les realizó el protocolo de manejo para sepsis neonatal temprana, siguiendo las recomendaciones de la guía de práctica clínica del Ministerio de Salud y Protección Social de Colombia ${ }^{19}$. Al ingreso de la unidad neonatal se tomaron muestras para dos hemocultivos aerobios, periféricos, de sitios de punción diferente y con técnica estéril. Para la toma, el laboratorio uso viales de hemocultivos BD BACTEC Peds PLUS/F Culture Vials (Soybean-Casein Digest Broth with Resins in a Plastic Vial), con un volumen mínimo de $1 \mathrm{cc}$ de sangre por cada frasco. Se inició manejo antimicrobiano 
para muestras independientes $\chi^{2}$, con comprobación de condiciones para la validez de la prueba y cuando era necesario aplicando correcciones como $\chi^{2}$ de Yates, entre otras. Se tomó como significativo un valor $\mathrm{p} d \mathrm{de}<0,05$. Las variables con valor $\mathrm{p}<0,2$ y aquellas consideradas por el equipo investigador como importantes para el ajuste de las asociaciones identificadas en el análisis bivariado, fueron ingresadas a un modelo de regresión logística binaria, teniendo como criterio de bondad de ajuste del modelo el criterio de Akaike. La fuerza y dirección de las asociaciones identificadas en el modelo de regresión logística se reportaron con su respectiva medida de asociación e intervalo de confianza de $95 \%$. En el objetivo de evaluar la sensibilidad y especificidad de la prueba diagnóstica en evaluación, se utilizó el resultado de PCR de manera cuantitativa, y mediante una curva ROC no paramétrica se estimó sensibilidad y especificidad, razones de verosimilitud y porcentaje de clasificación correcta para cada punto de corte posible. Para la determinación del punto de corte óptimo se utilizó como medida de identificación la maximización del índice de Youden. Se evaluó el desempeño de combinar dos PCR positivas tomadas de forma seriada a las 12 y $48 \mathrm{~h}$ del nacimiento tomando el punto de corte de referencia $(6 \mathrm{mg} / \mathrm{L})$ y el punto de corte óptimo calculado y se determinó sensibilidad, especificidad y razones de verosimilitud. Los análisis se realizaron con Stata All 12, Software Estadístico R y el paquete Optimal Cutpoint, desarrollado por López-Ratón y Rodríguez-Álvarez ${ }^{20}$. $\mathrm{dL}$ ); con al menos dos valores alterados, se incluyeron dentro de este grupo (sepsis) como sepsis probable ${ }^{4}$. Los pacientes que no cumplían criterio anterior alguno, se les descartó y se les incluyó dentro del grupo de comparación (no sepsis). Para el aislamiento bacteriano se usó un sistema de cultivo de sangre automatizado BACTEC 9050. $\mathrm{Al}$ identificar la positividad, se repicó sobre agar sangre, agar chocolate y EMB (eosina, azul de metileno, "eosinmethylene blue") por 24 a 48 h e hicieron una preparación directa con Gram. Los microorganismos aislados en placas de cultivo fueron identificados bioquímicamente. La prueba de susceptibilidad a antimicrobianos se realizó según el procedimiento estándar de laboratorio para todos los hemocultivos positivos.

\section{Análisis estadístico}

Se realizó un análisis exploratorio para identificar distribuciones de las variables cuantitativas, tanto continuas como discretas. En las variables continuas se realizaron pruebas estadísticas para comprobar su distribución normal y definir de esta manera su mejor presentación en estadística descriptiva. Las variables cuantitativas algunas fueron categorizadas según puntos de corte establecidos para la descripción de índole clínico. Se realizaron comparaciones de proporciones para la identificación de variables asociadas a sepsis, utilizando comparaciones

\section{Resultados}

El estudio incluyó 198 pacientes que cumplían los criterios de ingreso; de ellos, 33 recibieron tratamiento con diagnóstico de sepsis neonatal temprana (12 sepsis probada, 21 sepsis probable). En la Tabla 1 se muestran las características de la población y la proporción de incidencia dentro de los que desarrollaron sepsis; la media de peso de los recién nacidos fue de $2.614 \mathrm{~g}$ (DE 106,5 , IC95\% 2.398,5-2.829,2) y 38,1 semanas para la edad gestacional (DE 0,14, IC 95\% 38,2-38,4). Eran asintomáticos $75,8 \%$ del total, pero todos los pacientes que desarrollaron sepsis presentaron al menos un síntoma clínico relacionado con la enfermedad. Dentro de la cohorte sepsis existe mayor proporción en la incidencia de reanimación $(77,8 \%, 7 / 9, \mathrm{p} 0,000)$, indicación de cuidado intensivo al ingreso $(52,6 \%, 10 / 19, \mathrm{p} 0,000)$ y necesidad de soporte ventilatorio $(88,9 \%, 8 / 9, \mathrm{p} 0,000)$. La media de días de hospitalización total en los participantes encontrada fue de 5,7 (7 vs 3, entre los que desarrollaron sepsis y los que fue descartada, p 0,000); que se correspondía con el número de días de antibioterapia que recibieron los pacientes. 
Tabla 1. Características sociodemográficas y clínicas de los recién nacidos y la proporción de incidencia dentro de los que desarrollaron sepsis

\begin{tabular}{|c|c|c|c|c|c|}
\hline & $\mathbf{n}$ & $(\%)$ & $\begin{array}{c}\mathrm{PI}^{*} \text { de sepsis } \\
\mathrm{n}(\%)\end{array}$ & n/total & $\mathbf{P}$ \\
\hline \multicolumn{6}{|l|}{ Sexo } \\
\hline Masculino & 125 & 63,1 & $22(17,7)$ & $125 / 198$ & 0,620 \\
\hline Femenino & 73 & 36,9 & $11(15,1)$ & $73 / 198$ & \\
\hline \multicolumn{6}{|l|}{ Tipo de afiliación } \\
\hline Subsidiado & 188 & 94,9 & $31(16,5)$ & $188 / 198$ & 0,817 \\
\hline Contributivo & 9 & 4,5 & $2(22,2)$ & 9/198 & \\
\hline Ninguno & 1 & 0,5 & $0 \quad(0)$ & $1 / 198$ & \\
\hline \multicolumn{6}{|l|}{ Signos y síntomas } \\
\hline Fiebre $\left(>38^{\circ} \mathrm{C}\right)$ & 4 & 2,0 & $1(25)$ & $4 / 198$ & 0,651 \\
\hline Hipotermia $\left(<36,5^{\circ} \mathrm{C}\right)$ & 5 & 2,5 & $0 \quad(0)$ & $5 / 198$ & 0,311 \\
\hline Letargia & 8 & 4,0 & $5(62,5)$ & 8/198 & $<0,001$ \\
\hline Bradicardia $(<100$ Lpm) & 6 & 3,0 & $5(83,3)$ & $6 / 198$ & $<0,001$ \\
\hline Taquicardia (> 180 Lpm) & 4 & 2,0 & $2(50)$ & $4 / 198$ & 0,071 \\
\hline Taquipnea (> 60 Rpm) & 13 & 6,6 & $7(53,8)$ & $13 / 198$ & $<0,001$ \\
\hline Hiporexia & 4 & 2,0 & $2(50)$ & $4 / 198$ & 0,071 \\
\hline Piel reticulada & 7 & 3,5 & $5(71,4)$ & $7 / 198$ & $<0,001$ \\
\hline Mal aspecto & 48 & 24,2 & $16(33,3)$ & $48 / 198$ & $<0,001$ \\
\hline Ictericia & 4 & 2,0 & $1(25)$ & $4 / 198$ & 0,651 \\
\hline \multicolumn{6}{|l|}{ Peso al nacer } \\
\hline $1.500-<2.500 \mathrm{~g}$ & 39 & 19,7 & $9(23,1)$ & $39 / 198$ & 0,362 \\
\hline $2.500-3.800 \mathrm{~g}$ & 151 & 76,3 & $22(14,6)$ & $151 / 198$ & \\
\hline$>3.800 \mathrm{~g}$ & 8 & 4,0 & $2(25)$ & $8 / 198$ & \\
\hline
\end{tabular}

Edad gestacional

$\begin{array}{lrrrrr}<37 \text { semanas } & 31 & 15,6 & 7(22,6) & 31 / 198 & 0,336 \\ 37-41 & 167 & 84,3 & 26(15,6) & 167 / 198 & \end{array}$

Apgar al minuto

$\begin{array}{lrrrrr}\text { Bajo }(<7) & 15 & 7,6 & 7(46,8) & 15 / 198 & <0,001 \\ \text { Adecuado } & 183 & 92,4 & 26(14,2) & 183 / 198 & \end{array}$

Apgar a los 5 minutos

$\begin{array}{lrccrc}\text { Bajo }(<7) & 4 & 2,0 & 4(100) & 193 / 198 & <0,001 \\ \text { Adecuado } & 196 & 98 & 29(15) & 4 / 198 & \\ \text { Necesidad de reanimación } & 9 & 4,5 & 7(77,8) & 9 / 198 & <0,001\end{array}$

*Pl: Proporción de incidencia *Lpm: latidos por minuto *Rpm: respiraciones por minuto.

\section{Información materna, control prenatal y atención del parto}

La media de edad al momento del parto fue 23,2 años (DE 0,4, IC95\% 22,3-24,1) con una paridad de 2,1 gestaciones (DE 1,57 IC95\% 1,9-2,3). Predominó el parto vaginal en $57 \%$ (113 vs 85 cesáreas); $47,4 \%$ de las gestaciones presentaron un mal control prenatal; $16,6 \%$ eran madres adolescentes (dentro de este grupo: $15,1 \%$ presentaron parto pretérmino, $50 \%$ tenían mal control prenatal, $55,9 \%$ desarrollaron rotura prematura de membranas, en $44,1 \%$ la vía de parto fue vaginal) y $49 \%$ de las madres eran primigestante $(28,9 \%$ adolescentes, $2,1 \%$ gestantes añosas). El común denominador dentro de las madres fue el bajo nivel socio-económico y la falta de cribado para $S$. agalactiae (a $1 \%$ de los embarazos se les realizó) y sólo una de las dos gestantes que se le practicó este cribado recibió profilaxis. De las mujeres gestantes, a $82,2 \%$ se les administraron antibioterapia al momento previo al parto con una indicación diferente a la profilaxis para $S$. agalactiae $(65,2 \%$ la indicación fue rotura prematura de membranas y $21,3 \%$ corioamnionitis).

Se encontró que tener Apgar bajo y haber requerido reanimación al nacimiento aumentan más el riesgo de presentar sepsis versus los que no desarrollaron (Tabla 2).

$\mathrm{Al}$ análisis multivariado existe importante significancia estadística a favor de desarrollar sepsis con presentar Apgar bajo al nacer y un mal control del embarazo (menor a 4 controles prenatales, incluye valor 0 , que corresponde a ausencia de control prenatal) (Tabla 3 ).

La incidencia de proporción entre los que desarrollaron sepsis fue de 0,44 (24/33) con una significancia estadística dada por un valor de p 0,000 (Tabla 4). Se utilizó para este análisis un valor positivo $\geq 10 \mathrm{mg} / \mathrm{L}$; referenciando que es el valor óptimo con mayor utilidad diagnóstica según la literatura médica actual ${ }^{21}$. El riesgo relativo (RR) para los pacientes con PCR inicial elevada fue de 7,062 (IC $95 \%$ 3,5-14,2).

La incidencia de proporción entre los que desarrollaron sepsis fue de 0,56 (23/41) con una significancia estadística dada por un valor de p 0,000 (Tabla 5). El RR para los pacientes con PCR de control elevada fue de 13,8 (IC $95 \%$ 6,0-31,7).

Se realizó un análisis entre sepsis y los diferentes parámetros de laboratorios estudiados (leucocitosis $\geq 34.000 / \mathrm{mm}^{3}$, leucopenia $\leq 5.000 / \mathrm{mm}^{3}$, neutrófilos inmaduros $>10 \%$, relación $\mathrm{I}$ : $\mathrm{T} \geq 0,2$, trombocitopenia $\leq 100.000 / \mathrm{mm}^{3}$, neutropenia $\leq 1000$ ); sólo se encontró una significancia con la presencia de trombocitopenia, con una incidencia de proporción entre los que desarrollaron sepsis de $0,75(3 / 4, \mathrm{p} 0,000)$. El RR para los pacientes con trombocitopenia fue de 2,6 (IC 95\% $1,2-5,5)$. 


\section{Investigación Clínica}

\begin{tabular}{|c|c|c|c|c|c|c|}
\hline & $\begin{array}{c}\text { P.I. * de sepsis } \\
\text { n (\%) }\end{array}$ & n/total & $\mathbf{R R}$ & $\mathrm{Pe}^{* *}$ & Pne*** & IC95\% RR \\
\hline \multicolumn{7}{|l|}{ Bajo peso al nacer $(<2.500 \mathrm{~g})$} \\
\hline Sí & $9(23,1)$ & $39 / 198$ & \multirow[b]{2}{*}{1,529} & \multirow[b]{2}{*}{0,231} & \multirow[b]{2}{*}{0,15} & \multirow{2}{*}{0,773 a 3,022} \\
\hline No & $24(15,1)$ & $159 / 198$ & & & & \\
\hline \multicolumn{7}{|l|}{ Pretérmino (< 37 semanas) } \\
\hline Sí & $7(22,6)$ & $31 / 198$ & \multirow[b]{2}{*}{1,45} & \multirow[b]{2}{*}{0,226} & \multirow[b]{2}{*}{0,16} & \multirow{2}{*}{0,691 a 3,004} \\
\hline No & $26(15,6)$ & $167 / 198$ & & & & \\
\hline \multicolumn{7}{|l|}{ Control prenatal } \\
\hline Mal control ( $\leq 4$ controles) & $11(11,8)$ & 93/198 & \multirow{3}{*}{0,565} & \multirow{3}{*}{0,118} & \multirow{3}{*}{0,21} & \multirow{2}{*}{0,29 a 1,1} \\
\hline Buen control & $22(20,9)$ & $105 / 198$ & & & & \\
\hline Fiebre materna $\left(\geq 38,3^{\circ} \mathrm{C}\right)$ & & & & & & \multirow{3}{*}{0,916 a 6,159} \\
\hline Sí & $3(37,5)$ & $8 / 198$ & \multirow[b]{2}{*}{2,375} & \multirow[b]{2}{*}{0,375} & \multirow[b]{2}{*}{0,16} & \\
\hline No & $30(15,8)$ & $190 / 198$ & & & & \\
\hline \multicolumn{7}{|l|}{ Infección urinaria materna } \\
\hline Sí & $2(9,5)$ & $21 / 198$ & \multirow[b]{2}{*}{0,544} & \multirow[b]{2}{*}{0,095} & \multirow[b]{2}{*}{0,18} & \multirow[t]{2}{*}{0,14 a 2,11} \\
\hline No & $31(17,5)$ & $177 / 198$ & & & & \\
\hline \multicolumn{7}{|l|}{ Vaginosis bacteriana materna } \\
\hline Sí & $1(5,6)$ & $18 / 198$ & \multirow[b]{2}{*}{0,313} & \multirow[b]{2}{*}{0,056} & \multirow[b]{2}{*}{0,18} & \multirow[t]{2}{*}{0,045 a 2,154} \\
\hline No & $38(17,8)$ & $180 / 198$ & & & & \\
\hline Corioamnionitis (infección intra & & & & & & \\
\hline Sí & $10(26,3)$ & $38 / 198$ & & & & 0,953 a 3,516 \\
\hline No & $23(14,4)$ & $160 / 198$ & 1,831 & 0,263 & 0,14 & \\
\hline Uso de antimicrobianos en la $n$ & spitalización & & & & & \\
\hline Sí & $24(14,7)$ & $163 / 198$ & & & & 0,233 a 0,909 \\
\hline No & $8(32,0)$ & 25/198 & 0,46 & 0,147 & 0,32 & \\
\hline Rotura prematura de membrar & & & & & & \\
\hline$\geq 18 \mathrm{~h}$ & $10(9,4)$ & $106 / 198$ & & & & 0,190 a 0,751 \\
\hline$<18 h$ & $23(25)$ & $92 / 198$ & 0,377 & 0,094 & 0,25 & \\
\hline Reanimación del recién nacido & & & & & & \\
\hline Sí & $7(46,7)$ & $15 / 198$ & & & & 1,719 a 6,277 \\
\hline No & $26(14,2)$ & $183 / 198$ & 3,285 & 0,467 & 0,14 & \\
\hline Apgar bajo $(<7)$ al minuto & & & & & & \\
\hline Sí & $7(77,8)$ & 9/198 & & & & 3,431 a 9,316 \\
\hline No & $26(13,8)$ & $189 / 198$ & 5,654 & 0,778 & 0,14 & \\
\hline
\end{tabular}

*PI: Proporción de incidencia; **Proporción (riesgo) de eventos Expuestos (pe); ***Proporción (riesgo) de eventos No expuestos (pne).

Tabla 3. Factores asociados con mayor riesgo de sepsis bacteriana en los recién nacidos atendidos en la UCI neonatal entre 2016 y 2017

\begin{tabular}{|c|c|c|c|c|}
\hline & Odds Ratio & Valor de p & & \\
\hline Controles prenatales ( $\leq 4$ controles) & 3,1 & 0,023 & 1,17 & 8,12 \\
\hline Fiebre materna & 3,9 & 0,109 & 0,74 & 2,12 \\
\hline Vaginosis bacteriana & 0,2 & 0,102 & 0,02 & 1,45 \\
\hline Corioamnionitis & 1,8 & 0,256 & 0,66 & 4,78 \\
\hline Antibioterapia en la madre al momento de la hospitalización & 2,3 & 0,031 & 1,08 & 4,91 \\
\hline Profilaxis de $S$. agalactiae & 0,7 & 0,310 & 0,31 & 1,45 \\
\hline Bajo peso al nacer $(<2.500 \mathrm{~g})$ & 2,0 & 0,240 & 0,64 & 5,98 \\
\hline Apgar al nacer $(<7)$ & 4,5 & 0,019 & 1,28 & 1,55 \\
\hline
\end{tabular}


Se logró el aislamiento bacteriano en $12 / 198$ pacientes $(6,06 \%)$. Entre los patógenos causantes de sepsis, hubo predominio de cocos grampositivos (Staphylococcus aureus [33,3\%] y Staphylococcus epidermidis [16,7\%), seguido por Klebsiella pneumoniae (16,7\%) y otras enterobacterias. Se definió el aislamiento de Staphylococcus coagulasa negativa como microorganismo causal

\begin{tabular}{|c|c|c|c|c|c|}
\hline & & & \multicolumn{2}{|c|}{ Valor de PCR inicial } & \multirow[t]{2}{*}{ Total* } \\
\hline & & & Normal & Alterada & \\
\hline \multirow[t]{2}{*}{ Sepsis neonatal } & Ausencia & $\begin{array}{l}\text { Recuento } \\
\% \text { del total }\end{array}$ & $\begin{array}{c}134 \\
93,7 \%\end{array}$ & $\begin{array}{c}30 \\
55,6 \%\end{array}$ & 164 \\
\hline & Presencia & $\begin{array}{l}\text { Recuento } \\
\% \text { del total }\end{array}$ & $\begin{array}{c}9 \\
6,3 \%\end{array}$ & $\begin{array}{c}24 \\
44,4 \%\end{array}$ & 33 \\
\hline Total & & $\begin{array}{l}\text { Recuento } \\
\% \text { del total }\end{array}$ & 143 & 54 & $\begin{array}{l}197 \\
100,0 \%\end{array}$ \\
\hline
\end{tabular}

De un paciente no se dispuso del valor inicial de PCR.

Tabla 5. Sepsis neonatal temprana vs. PCR de control (a las 48 h)

\begin{tabular}{|c|c|c|c|c|c|}
\hline & & & \multicolumn{2}{|c|}{ Valor de PCR inicial } & \multirow[t]{2}{*}{ Total } \\
\hline & & & Normal & Alterada & \\
\hline \multirow[t]{2}{*}{ Sepsis neonatal } & Ausencia & $\begin{array}{l}\text { Recuento } \\
\% \text { del total }\end{array}$ & $\begin{array}{c}142 \\
95,9 \%\end{array}$ & $\begin{array}{c}18 \\
43,9 \%\end{array}$ & 160 \\
\hline & Presencia & $\begin{array}{l}\text { Recuento } \\
\% \text { del total }\end{array}$ & $\begin{array}{c}6 \\
4,1 \%\end{array}$ & $\begin{array}{c}23 \\
56,1 \%\end{array}$ & 29 \\
\hline Total & & $\begin{array}{l}\text { Recuento } \\
\% \text { del total }\end{array}$ & 148 & 41 & $\begin{array}{c}189 \\
100,0 \%\end{array}$ \\
\hline
\end{tabular}

De un paciente no se dispuso del valor inicial de PCR.

Tabla 6. Características operativas ante la combinación de resultados de PCR con dos puntos de corte diferentes

\begin{tabular}{|c|c|c|c|c|c|c|}
\hline \multirow[b]{3}{*}{ Sensibilidad } & \multicolumn{3}{|c|}{$\begin{array}{c}\text { Combinación de dos PCR } \\
\geq 11,1 \mathrm{mg} / \mathrm{L}\end{array}$} & \multicolumn{3}{|c|}{$\begin{array}{c}\text { Combinación de dos PCR } \\
\geq 6 \mathrm{mg} / \mathrm{L} \text { (valor de referencia } \\
\text { institucional) }\end{array}$} \\
\hline & \multirow{2}{*}{$\begin{array}{l}\text { Valor } \\
100,0\end{array}$} & \multicolumn{2}{|c|}{ IC95\% } & \multirow{2}{*}{$\begin{array}{l}\text { Valor } \\
100,0\end{array}$} & \multicolumn{2}{|c|}{ IC95\% } \\
\hline & & 89,4 & 100,0 & & 89,4 & 100,0 \\
\hline Especificidad & 75,2 & 67,8 & 81,5 & 62,4 & 54,6 & 69,8 \\
\hline VPP & 44,6 & 33,0 & 56,6 & 34,7 & 25,3 & 45,2 \\
\hline VPN & 100,0 & 97,1 & 100,0 & 100,0 & 96,5 & 100,0 \\
\hline Área ROC & 0,9 & 0,8 & 0,9 & 0,8 & 0,8 & 0,8 \\
\hline $\operatorname{LR}(+)$ & 3,9 & 3,0 & 5,2 & 2,6 & 2,1 & 3,2 \\
\hline $\operatorname{LR}(-)$ & 0,020 & 0,001 & 0,308 & 0,024 & 0,002 & 0,370 \\
\hline
\end{tabular}

si hubiera su recuperación en los dos hemocultivos y/o si el crecimiento microbiológico en los cultivos fuera rápido $(<$ de $24 \mathrm{~h}$ ) y/o estuviera relacionado con dispositivos médicos que generarán biopelícula bacteriana (p. ej.: en catéteres umbilicales).

\section{Validez diagnóstica de la PCR en la sepsis neonatal temprana}

En el objetivo de determinar la utilidad de la PCR, los valores de corte con la eficiencia diagnóstica óptima derivadas de la curva de ROC fueron $11,1 \mathrm{mg} / \mathrm{L}$, con un índice de Youden de 0,55. Las características operativas del punto de corte óptimo elegido por maximización del índice de Youden mostraron una sensibilidad, especificidad, VPP, VPN, un índice de probabilidad positiva y un índice de probabilidad negativa, de 72,2 - 82,4 - 45,2 - 93,7 - 4,1 y 0,3, respectivamente; con un área bajo la curva de 0,78 (IC95\% 0,71-0,83). Para un punto de corte mayor a $6,0 \mathrm{mg} / \mathrm{L}$ (valor de referencia del laboratorio) mostró una sensibilidad, especificidad, VPP, VPN, un índice de probabilidad positiva y un índice de probabilidad negativa, de 72,7 - 75 - 36,4 - 93,2 - 2,8 y 0,3, respectivamente. Realizando combinación de puntos de corte de PCR de mayor o igual a $6 \mathrm{mg} / \mathrm{L}$ y mayor o igual a 11,1 mg/L (Tabla 6), se evaluó la utilidad diagnóstica de dos valores de PCR seriadas; evidenciado que dos resultados negativos aumentan el VPN hasta alcanzar $100 \%$ (IC95\% 97,1-100,0).

\section{Discusión}

La PCR no debe ser un examen de rutina en todos los recién nacidos, nuestros resultados encontraron que la sensibilidad de la prueba oscila en un amplio rango y confiere un porcentaje alto de falsos positivos. En la fase aguda, las concentraciones de muchas proteínas (haptoglobina, fibrinógeno y PCR) aumentan en respuesta a la inflamación, infección, trauma, asfixia y daño tisular ${ }^{22}$. Existen factores maternos y fetales que pueden afectar el valor de la PCR neonatal y deben tenerse en cuenta al considerarla como un único indicador de $\operatorname{sepsis}^{23}$; la rotura de membranas induce un aumento de los valores $(0,4 \%$ por hora), el trabajo de parto activo (14,5\% por hora), la administración materna de corticosteroides (40\%), o el uso de antimicrobianos intraparto (28\%), o la corioamnionitis sin enfermedad invasora fetal o neonatal; además, el traumatismo, la lesión tisular isquémica, la hemólisis o el síndrome de aspiración de meconio pueden provocar su aumento en las primeras 24 a $48 \mathrm{~h}$ de vida $^{7}$. Cuando analizamos un solo valor de PCR positivo tomado a las $12 \mathrm{~h}$ de vida, utilizando el valor de referencia institucional, se encontró un valor de sensibilidad bajo; estos hallazgos son similares a lo reportado por Himayun y cols., valores de sensibilidad, especificidad, VPP y VPN a las $0 \mathrm{~h}$ de 
nuevos marcadores, la PCR hasta ahora sigue siendo el índice más utilizado ${ }^{33}$; si la comparamos con otras pruebas diagnósticas, procalcitonina, tiene más sensibilidad, pero carece de especificidad. La sensibilidad media para sepsis temprana, sepsis tardía y sepsis temprana + tardía fue de $73,6 \%, 88,9 \%$ y $76,5 \%$, en comparación con $65,6 \%$, $77,4 \%$ y $66,4 \%$ para PCR, respectivamente y la especificidad media de procalcitonina y PCR fue $82,8 \%$ versus $82,7 \%$ para sepsis temprana, $75,6 \%$ versus $81,7 \%$ para tardía y $80,4 \%$ versus $91,3 \%$ para temprana + tardía $^{10}$.

La presepsina es otro biomarcador de sepsis, pero su utilidad se limita en sepsis tardía y para evaluar la respuesta al tratamiento (sensibilidad de $94 \%$, especificidad de $100 \%$, coeficiente de probabilidad negativa de $0,05 \mathrm{y}$ el coeficiente de probabilidad positiva infinito $)^{34}$.

Al analizar el recuento absoluto de leucocitos, el número total de neutrófilos y la proporción de neutrófilos inmaduros, ninguna de estas pruebas es particularmente útil para el diagnóstico de sepsis neonatal temprana ${ }^{12}$. La neutropenia tiene mayor especificidad, pero la definición depende de la edad gestacional, y de otros factores, lo que dificulta su estandarización ${ }^{35}$. La relación de leucocitos inmaduros/ totales mayores a 0,2 , tiene un VPN alto, pero un VPP muy bajo ${ }^{36}$. Todos estos hallazgos en el hemograma fueron similares a nuestro estudio, mostrando poca utilidad diagnóstica. La única gran diferencia la encontramos con trombocitopenia, que se relacionó con aumento en la probabilidad de desarrollar sepsis, difiriendo con la mayoría de los estudios que reportan que el recuento total de plaquetas bajo no es muy específico o sensible para el diagnóstico ${ }^{37}$.

Los factores de riesgo a que están expuestos los recién nacidos de nuestra población de referencia, aunque incluyen los nombrados en la literatura médica ${ }^{38}$, existen otros factores muy importantes a considerar influenciados por nuestra condición socio-económica y las deficiencias en los sistemas de salud, como la ausencia de control prenatal y/o mal control prenatal. Para validar dichos resultados, se necesitan estudios que evalúen dicha asociación en nuestra población. De acuerdo a la Encuesta Nacional de Demografía y Salud 2018, de Colombia, pese a los aumentos de la cobertura en la atención materna en los últimos años, se estima que aproximadamente un cuarto de mujeres embarazadas aún no accede a atención, esto es, sin control prenatal alguno ${ }^{39}$.

Streptococcus agalactiae es el microorganismo que se ha observado como prevalente, seguido de los bacilos gramnegativos, que muestran un creciente número en los últimos años, con un aumento de la mortalidad asociada por Escherichia coli, principalmente ${ }^{40}$. Nuestro estudio tiene mayor similitud a lo descrito en la literatura médica nacional con relación a la frecuencia. En contraposición, en el año 2008 se publicó un estudio realizado en una unidad neonatal de Medellín y el microorganismo más 
frecuente aislado fue Staphylococcus spp. coagulasa negativa $(40,2 \%)$, seguido de los bacilos gramnegativos $(33,6 \%)^{41}$.

\section{Conclusiones}

La PCR es de utilidad para complementar la evaluación a todos los recién nacidos con una infección potencial y se debe realizar como estudio adicional a la obtención de hemocultivos. Dos valores de PCR negativos en ausencia de manifestaciones clínicas y de hemocultivos positivos tienen un alto VPN y un índice de probabilidad negativa a favor de excluir la infección con una alta certeza y/o de descontinuar la terapia antimicrobiana.

\section{Referencias bibliográficas}

1.- Lehtonen L, Gimeno A, Parra-Llorca A, Vento M. Early neonatal death: A challenge worldwide. Semin Fetal Neonatal Med. 2017; 22 (3): 153-60. doi: 10.1016/j.siny.2017.02.006.

2.- Tzialla C, Manzoni P, Achille C, Bollani L, Stronati M, Borghesi A. New diagnostic possibilities for neonatal sepsis. Am J Perinatol. 2018; 35 (6): 575-7. doi: 10.1055/s-00381639361.

3.- Iroh Tam P Y, Bendel C M. Diagnostics for neonatal sepsis: current approaches and future directions. Pediatr Res. 2017; 82 (4): 574-83. doi: 10.1038/pr.2017.134.

4.- Zea-Vera A, Ochoa T J. Challenges in the diagnosis and management of neonatal sepsis. $\mathrm{J}$ Trop Pediatr. 2015; 61(1): 1-13. doi: 10.1093/tropej/fmu079.

5.- Abdel Ghany E A, Ali A A. Empirical antibiotic treatment and the risk of necrotizing enterocolitis and death in very low birth weight neonates. Ann Saudi Med. 2012; 32 (5): 521-6. doi: 10.5144/0256-4947.2012.521.

6.- Khan F. C-reactive protein as a screening biomarker in neonatal sepsis. J Coll Physicians Surg Pak. 2019; 29 (10): 951-3. doi: 10.29271/ jcpsp.2019.10.951.

7.- Mjelle A B, Guthe H J T, Reigstad H, BjørkeMonsen A L, Markestad T.

Serum concentrations of C-reactive protein in healthy term-born Norwegian infants 48-72 hours after birth. Acta Paediatr. 2019; 108 (5): 849-54. doi: 10.1111/apa.14578.

8.- Macallister K, Smith-Collins A, Gillet H, Hamilton L, Davis J. Serial C-reactive protein measurements in newborn infants without evidence of early-onset infection. Neonatology. 2019; 116(1): 85-91. doi: 10.1159/000497237.

9.- Benitz W E, Han M Y, Madan A, Ramachandra P. Serial serum C-reactive protein levels in the diagnosis of neonatal infection. Pediatrics. 1998; 102 (4): E41. doi: 10.1542/ peds.102.4.e41.

10.- Eschborn S, Weitkamp J H. Procalcitonin versus $\mathrm{C}$-reactive protein: review of kinetics and performance for diagnosis of neonatal sepsis. J Perinatol. 2019; 39(7): 893-903. doi: 10.1038/s41372-019-0363-4.

11.- Chiesa C, Pacifico L, Osborn J F, Bonci E, Hofer N, Resch B. Early-onset neonatal sepsis: still room for improvement in procalcitonin diagnostic accuracy studies. Medicine (Baltimore). 2015; 94(30): e1230. doi: 10.1097/ MD.0000000000001230.

12.- Simonsen K A, Anderson-Berry A L, Delair S F, Davies HD. Early-onset neonatal sepsis. Clin Microbiol Rev. 2014; 27(1): 21-47. doi: 10.1128/CMR.00031-13.

13.- Memar M Y, Alizadeh N, Varshochi M, Kafil H S. Immunologic biomarkers for diagnostic of early-onset neonatal sepsis. J Matern Fetal Neonatal Med. 2019; 32(1): 143-53. doi: 10.1080/14767058.2017.1366984.

14.- Polin R A and the Committee on Fetus and Newborn. Management of neonates with suspected or proven early-onset bacterial sepsis Pediatrics. 2012; 129 (5): 1006-15. doi: https:// doi.org/10.1542/peds.2012-0541.

15.- Connell T G, Rele M, Cowley D, Buttery J $\mathrm{P}$, Curtis N. How reliable is a negative blood culture result? Volume of blood submitted for culture in routine practice in a children's hospital. Pediatrics. 2007; 119 (5): 891-6. doi: 10.1542/peds.2006-044

16.- Hershkovich-Shporen C, Bardenstein R, Blickstein I, Shinwell ES, Flidel-Rimon O. Maternal intrapartum antibiotic treatment continues to exert a bactericidal effect on the umbilical cord and peripheral venous blood of newborn infants. Acta Paediatr. 2017 106 (11): 1767-71. https://doi.org/10.1111/ apa.13982.

17.- Hincu M A, Zonda G I, Stanciu G D, Nemescu D, Paduraru L. Relevance of biomarkers currently in use or research for practical diagnosis approach of neonatal early-onset sepsis. Children (Basel). 2020; 7(12): 309. doi: 10.3390/children7120309.

18.- Mulinganya G, Balolebwami S, Zigabe S, Mongane J, Nianci I, Burume A, et al. Evaluation of a turbidimetric C-reactive protein assay to monitor early-onset neonatal sepsis in South Kivu (Democratic Republic of the Congo) [published online ahead of print, 2020 May 5]. Clin Chem Lab Med. 2020; 59(3): 62530. doi: 10.1515/cclm-2020-0309

19.- Centro Nacional de Investigación en Evidencia y Tecnologías en Salud. Guías de atención integral. Convenio 500/2009. Alianza Cinets; 2014

20.- López-Ratón M, Rodríguez-Álvarez M X,
Cadarso-Suárez C, Gude-Sampedro F. Optimal cutpoints: an R package for selecting optimal cutpoints in diagnostic tests. J Stat Softw 2014; 61 (8): 1-36. doi: http://dx.doi.org/10.18637/jss. v061.i08.

21.- Aydemir C, Aydemir H, Kokturk F, Kulah C, Mungan AG. The cut-off levels of procalcitonin and $\mathrm{C}$-reactive protein and the kinetics of mean platelet volume in preterm neonates with sepsis BMC Pediatr. 2018; 18(1): 253. doi: 10.1186/ s12887-018-1236-2.

22.- Kite P, Millar M R, Gorham P, Congdon P. Comparison of five tests used in diagnosis of neonatal bacteraemia. Arch Dis Child. 1988; 63 (6): 639-43. doi: 10.1136/adc.63.6.639.

23.- Nesbitt R E Jr, Hays R C, Mauro J. The behavior of C-reactive protein in pregnant and puerperal women, fetal blood, and in the newborn infant under normal and abnormal conditions. Obstet Gynecol. 1960; 16: 659-66. PMID: 13728395.

24.- Himayun M, Ahmad S, Rasool A. Role of c-reactive protein in early onset neonatal sepsis. Internet J Pediatr Neonatol. 2009; 11 (2): https://pdfs.semanticscholar.org/af06/ de12f234b668d697c0bc16de3258321c76fa. pdf? ga $=2.134613171 .372067911 .1615121795$ 755259746.1598638586 .

25.- Kordek A, Łoniewska B, Podraza W, Nikodemski T, Rudnicki J. Usefulness of estimation of blood procalcitonin concentration versus $\mathrm{C}$-reactive protein concentration and white blood cell count for therapeutic monitoring of sepsis in neonates Postepy Hig Med Dosw (Adv Hygien Exp Med) (Online). 2014; 68: 1516-23. doi: 10.5604/17322693.1133101.

26.- Barua C, Anwar M N, M Shahidullah M, Hossain S, Barua S, Chowdhuryf N. Role of serial C-reactive protein (CRP) in relation to total leukocyte count, platelet count \& blood culture for early diagnosis of neonatal septicemia in Developing Countries. J Banagladesh Coll Phys Surg 2014; 32: 61-5. doi: 10.3329/jbcps.v32i2.26032.

27.- Kumar N, Dayal R, Singh P, Pathak S, Pooniya $\mathrm{V}$, Goyal A, et al. A comparative evaluation of presepsin with procalcitonin and CRP in diagnosing neonatal sepsis. Indian J Pediatr. 2019; 86(2): 177-9. doi: 10.1007/s12098-0182659-3. 


\section{Investigación Clínica}

28.- Younis S, Sheikh M, Raza A. Diagnostic accuracy of C-reactive protein in neonatal sepsis. J. Biores Manag. 2014;1 (1): 33-42. doi: 10.35691/JBM.4102.0001.

29.- Hengst J M. The role of C-reactive protein in the evaluation and management of infants with suspected sepsis. Adv Neonatal Care. 2003; 3 (1): 3-13. doi: 10.1053/adnc.2003.50010.

30.- Sharma D, Farahbakhsh N, Shastri S, Sharma P. Biomarkers for diagnosis of neonatal sepsis: A literature review. J Matern Neonatal Med. 2018; 31: 1646-59. doi: 10.1080/14767058.2017.1322060.

31.- Rashwan N I, Hassan M H, El-Deen Z M M, El-Abd Ahmed A. Validity of biomarkers in screening for neonatal sepsis - A single center - hospital based study. Pediatr Neonatol. 2019; 60 (2): 149-55. doi: 10.1016/j. pedneo.2018.05.001

32.- Morad E A, Rabie R A, Almalky M A, Gebriel M G. Evaluation of procalcitonin, C-reactive protein, and interleukin- 6 as early markers for diagnosis of neonatal sepsis. Int J Microbiol. 2020; 2020:8889086. doi: $10.1155 / 2020 / 8889086$.
33.- Hedegaard S S, Wisborg K, Hvas A M. Diagnostic utility of biomarkers for neonatal sepsis-a systematic review. Infect Dis (Lond). 2015; 47 (3): 117-24. doi: $10.3109 / 00365548.2014 .971053$.

34.- Poggi C, Bianconi T, Gozzini E, Generoso M, Dani C. Presepsin for the detection of late onset sepsis in preterm newborns. Pediatrics. 2015; 135 (1): 68-75. doi: 10.1542/peds.2014-1755.

35.- Shah J, Balasubramaniam T, Yang J, Shah PS. Leukopenia and neutropenia at birth and sepsis in preterm neonates of $<32$ weeks' gestation. Am J Perinatol. 2020 Nov 23. doi: 10.1055/s0040-1721133.

36.- Schmutz N, Henry E, Jopling J, Christensen R D. Expected ranges for blood neutrophil concentrations of neonates: the Manroe and Mouzinho charts revisited. J Perinatol. 2008; 28 (4): 275-81. doi: 10.1038/sj.jp.7211916.

37.- Arif S H, Ahmad I, Ali S M, Khan H M Thrombocytopenia and bacterial sepsis in neonates. Indian J Hematol Blood Transfus. 2012; 28 (3): 147-51. doi: 10.1007/s12288-0110118-7.
38.- Adatara P, Afaya A, Salia SM, Afaya RA, Konlan KD, Agyabeng-Fandoh E, et al. Risk factors associated with neonatal sepsis: a case study at a specialist hospital in Ghana. Scientific World J. 2019; 9369051. https://doi.org/10.1155/2019/9369051.

39.- PROFAMILIA. Encuesta nacional de demografía y salud-ENDS: I Tomo Componente demográfico. Colombia: PROFAMILIA; 2018. https://profamilia.org.co/ wp-content/uploads/2018/12/ENDS-TOMO-I. pdf.

40.- Schrag S J, Farley M M, Petit S, Reingold A, Weston E J, Pondo T, et al. Epidemiology of invasive early-onset neonatal sepsis, 2005 to 2014. Pediatrics. 2016; 138 (6): e20162013. doi: https://doi.org/10.1542/ peds.2016-2013.

41.- Betancur L, Jiménez K, Galindo A, Cornejo W. Características epidemiológicas, clínicas y microbiológicas, y mortalidad de neonatos con sepsis comprobada en el Hospital Universitario San Vicente de Paúl, Medellín, 2003-2005. Iatreia (Internet). 2008; 21(1): S13. http://www. redalyc.org/articulo.oa?id=180513866010. 